\title{
Predicting the Temperature and Flow Distribution in a Direct Oil-Cooled Electrical Machine with Segmented Stator
}

\author{
R. Camilleri, D.A. Howey, Member, IEEE, M.D. McCulloch, Member, IEEE
}

\begin{abstract}
This paper presents a computationally efficient thermo-fluid model to predict the temperature and flow distribution in an oil-cooled electrical machine with a segmented stator. The Yokeless and Segmented Armature axial flux machine was used as a case study in which a numerical model was set up and validated to within $6 \%$ of experimental results. The model was adapted to predict the temperature distribution of the segmented stator of a machine, identifying the hotspot temperatures and their location. Changes to the flow geometry on the stator temperature distribution were investigated. It was shown how by carefully controlling the flow distribution in the stator, the temperature distribution is improved and the hot spot temperature is reduced by $13 \mathrm{~K}$. This benefits the machine by doubling the insulation lifetime or by increasing the current density by approx. $7 \%$.
\end{abstract}

Index Terms - Electric machines, thermal analysis, thermal modeling, fluid dynamics, numerical simulation, thermal resistance, temperature control, fluid flow control, predictive model

\section{NOMENCLATURE}

$\mathrm{A}_{\mathrm{f}}$ Flow area

c Specific heat capacity

$\mathrm{D}_{\mathrm{h}}$ Hydraulic diameter

$\left[\mathrm{m}^{2}\right]$

$d Q_{j}$ Incremental flow correction

$\Delta_{j} \quad$ Head-flow ratio

$\mathrm{E}_{\mathrm{g}} \quad$ Total heat loss generated

f Friction factor

$\mathrm{f}_{\text {app }}$ Apparent friction factor

$\mathrm{g}$ Acceleration due to gravity

$\mathrm{h}_{\mathrm{f}}$ Head loss

I Current

k Thermal conductivity

K Head loss coefficient

1 Pipe length

$\mathrm{L}_{\mathrm{e}} \quad$ Entry length

$\mu \quad$ Dynamic viscosity

$v \quad$ Kinematic viscosity

$\mathrm{p} \quad$ Wetted perimeter

P Electrical Power

Pr Prandtl number

Q Flow rate

Re Reynolds number

Manuscript received January 27, 2015; revised May 3, 2015 and June 8, 2015; accepted July 2, 2015.

Copyright (c) 2015 IEEE. Personal use of this material is permitted. However, permission to use this material for any other purposes must be obtained from the IEEE by sending a request to pubs-permissions@ieee.org.

R. Camilleri, D.A. Howey and M.D. McCulloch are with the Energy and Power Group, Dept. of Eng. Sc., University of Oxford. (email: robert.camilleri@eng.ox.ac.uk; malcolm.mcculloch@eng.ox.ac.uk)

$\begin{array}{lll}\mathrm{R}_{\text {th }} & \text { Thermal resistance } & {[\mathrm{K} / \mathrm{W}]} \\ \rho & \text { Density } & {\left[\mathrm{kg} / \mathrm{m}^{3}\right]} \\ \mathrm{T} & \text { Temperature } & {[\mathrm{K}]} \\ \mathrm{u} & \text { Uncertainty } & \\ \mathrm{U} & \text { Overall heat transfer coefficient } & {\left[\mathrm{W} / \mathrm{m}^{2} \mathrm{~K}\right]} \\ \mathrm{v}_{\mathrm{f}} & \text { Fluid velocity } & {[\mathrm{m} / \mathrm{s}]} \\ \mathrm{v} & \text { Volume } & {\left[\mathrm{m}^{3}\right]} \\ \mathrm{V} & \text { Voltage } & {[\mathrm{V}]}\end{array}$

\section{INTRODUCTION}

$\mathrm{R}$ ECENT developments in axial flux permanent magnet machines enable higher torque densities and higher efficiencies making them suitable for applications such as road transportation or wind energy generation [1]-[3]. The quest to improve torque density requires that both the electromagnetic and thermal aspects of the machine are optimized. While there are numerous papers demonstrating improvement in electromagnetics, studies demonstrating improvements in the thermo-fluids aspects of electrical machines are fewer [4]. The losses in electrical machines generate heat which if not removed raises the temperature of its components. In the stator, the copper $\mathrm{I}^{2} \mathrm{R}$ losses increase the temperature of the windings resulting in an increase in resistance. The iron suffers from eddy and hysteresis losses. These reduce the efficiency of the machine. As the winding insulation is rated to a maximum operating temperature, it degrades by the Arrhenius chemical reaction [5]. Therefore the hottest spot in the stator limits the machine life and rating.

Accurate thermal modeling of electrical machines allows proper choice of materials, avoids unnecessary de-rating and reduces safety factors thus achieving higher torque densities. Thermal modeling is performed either through analytical methods such as lumped parameter (LP) models [6],[7], or numerical techniques such as finite element analysis [9]-[12] and computational fluid dynamics (CFD) [13]-[17]. LP models simplify spatial temperature distribution in solids. Although they require an initial effort to setup, they are fast to solve. Their application may sometimes be insufficient as they fail to provide an accurate temperature distribution of the machine [18], [19]. Moreover a number of input parameters such as the heat transfer coefficient (HTC) are required. This is difficult to determine and is obtained from experiments [17], [20], [21], empirical correlations of ideal geometries [22], [23], or CFD simulations [15]-[17]. CFD models provide detailed information and insight into the fluid behavior but are time consuming [24]. Therefore CFD models are often limited to specific components to extract the HTC values while the overall machine thermal simulation is performed by LP models [24]. The dependence of LP models on HTC input values often imply that improvements to the flow geometry and the thermal path of the machine requires a series of 
alternating simulations between CFD and LP models. Therefore alterations during the design procedure is time consuming and costly. This is especially true for direct cooling methods in which the heat transfer in the stator is a function of the flow distribution.

This paper addresses this problem by coupling together two conventional techniques - the flow network model and the lumped parameter model. The flow network model is used to determine the flow distribution in the stator from which the HTC values are estimated. These are inputted into the lumped parameter model, which solves the temperature distribution in the stator. The novelty of coupling a flow network model and a lumped parameter thermal model results in a fast but accurate simulation tool that identifies which of the segmented pole pieces will be at the highest temperature. During the early design stages of the machine the thermal designer can change the flow geometry to alter the temperature distribution in the stator pole pieces, therefore investigate a number of 'what if' scenarios in a very short time. The paper uses the Yokeless And Segmented Armature (YASA) electrical machine [1] as a case study and is therefore organized in the following manner. Section II presents a description of the machine and the cooling arrangement, thus setting the boundary conditions to which the model is applied. Section III presents the flow network model, the lumped parameter thermal model and the coupling between the two. Section IV describes the experimental quarter-motor test rig. The numerical model is validated with experimental results in Section $\mathrm{V}$. The model is adapted to simulate a full machine stator in Section VI, in which improvements to the motor design are suggested. Finally Section VII provides a discussion of the work presented in this paper, showing that by reducing the hot spot temperature the lifetime of the machine can be improved or the current density increased.

\section{The Yasa Machine: A Test CAse Study}

The YASA machine, shown in Fig. 1, is derived from the NS Torus-S topology. By removing the stator yoke, enlarging the pitch of the teeth and wrapping a high fill factor short end winding coils around each of the individual stator poles, the iron in the stator is reduced by around $50 \%$. This increases the torque density by around $20 \%$ when compared to other axial flux machines. The peak efficiency can be maintained at over $95 \%[1]$.

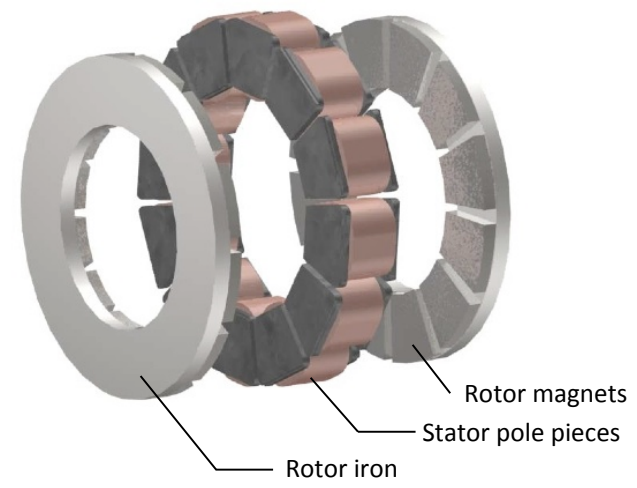

Fig. 1. Schematic of the YASA topology developed in [1]
The segmented stator design allows each pole piece to be wound separately. The stator is therefore easily assembled in its housing. This simplifies the manufacturing process, reducing the production costs of the machine, [25]. Furthermore, the ability to repair winding faults in such designs is improved, as highlighted in [26]. Segmented stators also offer the benefits of undertaking thermal analysis on a single pole piece [27], speeding up the thermal design of the machine. This architecture has recently received increasing attention and several variants can be found in the literature [2], [28]-[30]. Throughout this work, the direct drive motor YASA-750 motor [31] is considered. The specifications of the motor are listed in Table I.

TABLE I

MACHINE SPECIFICATIONS

\begin{tabular}{ll}
\hline \hline Machine name & YASA750 \\
Peak power & $100 \mathrm{~kW}$ \\
Peak torque & $750 \mathrm{~N} \cdot \mathrm{m}$ \\
Continuous power & $55 \mathrm{~kW}$ \\
Continuous torque & $400 \mathrm{~N} \cdot \mathrm{m}$ \\
Peak efficiency & $94 \%$ \\
\hline
\end{tabular}

Each stator pole piece of the YASA machine is made from concentrated windings of square cross section wire. Epoxy is typically injected in the windings to fill the air gaps, which also leaves the surfaces of the pole pieces smooth. In this machine, the stator is enclosed in a glass fiber casing allowing liquid coolant to be injected into the stator in direct contact with the windings. Flow stoppers are used to avoid the flow bypassing around the periphery, dividing the machine into four similar sections as shown in Fig. 2. In this respect the liquid flow distribution in the stator is similar to that of a parallel flow liquid cooled heat sink used for cooling high power density electronics. The stator's lack of a physical back plate gives the individual pole pieces a relatively low thermal mass and makes them very sensitive to the liquid flow distribution within the stator.

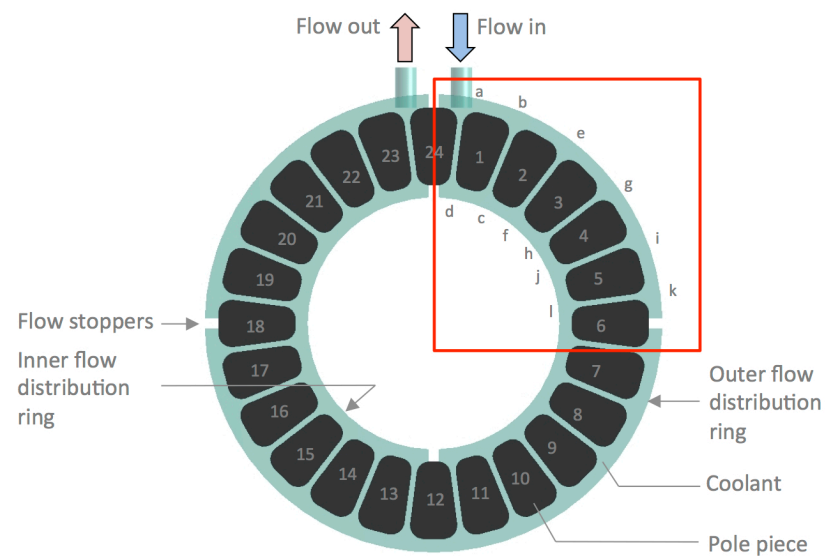

Fig. 2. Schematic of the YASA direct liquid cooled stator. Highlighted: Quadrant replicated for testing in Section IV

III. The Thermo-Fluid Numerical Model

A. The iterative flow network model

The head loss across a pipe $h_{\mathrm{f}}$ varies with flow rate $Q$ as 
described by:

$$
h_{f}=\frac{f l V^{2}}{2 g D_{h}}=\frac{f l Q^{2}}{2 g D_{h} A_{f}^{2}}
$$

For a known flow rate, the pressure drop across a single pipe can be calculated directly. The application of (2) to determine the pressure losses in through flow electrical machine was demonstrated in [23], [32], [33]. However in a closed circuit flow network, the total head loss of the system is equivalent to the sum of the pressure drops along any path connecting the inlet and the outlet, and is the same irrespective of the path. The head loss is therefore dependent on the flow distribution within the system and can only be solved through an iterative procedure. The iterative technique to determine the flow distribution in fluid networks is described in [34].

Flow distribution in pipe networks is analyzed by following simple rules based on Kirchoff's laws and following the continuity equation:

- The algebraic sum of the flows at any junction is zero

- The algebraic sum of the pressure drop around any closed loop is zero.

After the network is divided into flow loops, a conventional flow direction in each loop and an initial flow distribution is decided. Positive and negative head losses are computed depending on the direction of the flows. The total head loss in each loop is algebraically determined from which an incremental correction in the flow is calculated. The following section describes how the iterative fluid network model was applied to liquid cooled stator of the YASA machine.

The flow network in the stator is converted into a pipe network as shown in Fig. 3.
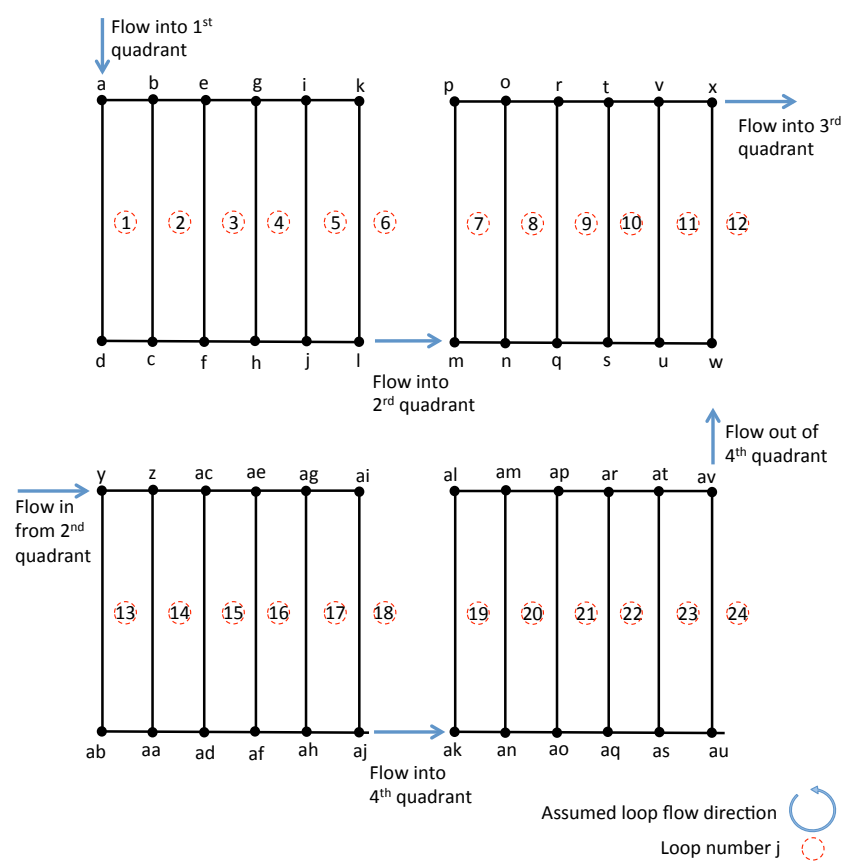

Fig. 3. Schematic of a simplified flow network for the machine.
Consider the first quadrant as an example; using an anticlockwise flow convention, the flow in each network loop $Q_{\mathrm{j}}$ is made from the flows of each pipe making the loop. Thus:

$$
Q=\left[\begin{array}{c}
Q_{\mathrm{j}=1} \\
Q_{\mathrm{j}=2} \\
Q_{\mathrm{j}=3} \\
\vdots \\
Q_{\mathrm{j}=6}
\end{array}\right]
$$

The flows in each loop can be describes as vectors:

$$
\begin{gathered}
Q_{\mathrm{j}=1}=\left[\begin{array}{llll}
-Q_{\mathrm{ab}} & -Q_{\mathrm{bc}} & Q_{\mathrm{cd}} & Q_{\mathrm{da}}
\end{array}\right] \\
Q_{\mathrm{j}=2}=\left[\begin{array}{llll}
-Q_{\mathrm{be}} & -Q_{\mathrm{ef}} & Q_{\mathrm{fc}} & Q_{\mathrm{cb}}
\end{array}\right] \\
\vdots \\
Q_{\mathrm{j}=6}=\left[\begin{array}{llll}
-Q_{\mathrm{ij}} & -Q_{\mathrm{kl}} & Q_{\mathrm{lj}} & Q_{\mathrm{ji}}
\end{array}\right]
\end{gathered}
$$

In the first iteration a uniform flow distribution through the number of channels $\mathrm{N}$ is assumed such that:

$$
Q_{\mathrm{da}}=Q_{\mathrm{bc}}=Q_{\mathrm{ef}}=\frac{Q_{\mathrm{in}}}{N}
$$

The flow in the peripheral rings is estimated by observing the conservation of mass and therefore can be found by:

$$
\begin{gathered}
Q_{\mathrm{ab}}=Q_{\mathrm{in}}-Q_{\mathrm{ad}} \\
Q_{\mathrm{be}}=Q_{\mathrm{ab}}-Q_{\mathrm{bc}} \\
Q_{\mathrm{fc}}=Q_{\mathrm{ab}}+Q_{\mathrm{dc}} \\
\vdots \\
Q_{\mathrm{ik}}=Q_{\mathrm{gi}}-Q_{i j} \\
Q_{\mathrm{jl}}=Q_{\mathrm{ij}}+Q_{\mathrm{hj}}
\end{gathered}
$$

In the following iterations an incremental correction in the flow for each loop $\mathrm{d} Q_{\mathrm{j}}$ is calculated using:

$$
\mathrm{d} Q_{\mathrm{j}}=\frac{-h_{\mathrm{f}, \mathrm{j}}}{2 \Delta_{\mathrm{j}}}
$$

$h_{\mathrm{fj}}$ is head loss in any single loop and is estimated from the vector summation of the head loss in the individual pipes $h_{\mathrm{fi}}$ :

$$
h_{\mathrm{f}, \mathrm{j}}=\sum h_{\mathrm{fi}}
$$

$h_{\mathrm{fi}}$ is dependent on the pipe or component geometry. Details of the values of $h_{\mathrm{fi}}$ are given in the following section.

$\Delta_{j}$ is head-flow ratio for any loop and is calculated using:

$$
\Delta_{\mathrm{j}}=\sum \frac{\left|h_{\mathrm{f}, \mathrm{i}}\right|}{\left|Q_{\mathrm{i}}\right|}
$$

When pipes are common to more than one loop, an algebraic correction based on the flow convention for each loop is made. The model was solved using MATLAB. Special attention was taken to preserve the flow and head loss vector based on the flow convention taken in each loop. The iterative process set to continue until the maximum change in the branches' flow varied less than $0.1 \%$. The iterative procedure to solve the flow distribution in each sector is shown in Fig. 4. The head loss in each pipe is heavily influenced by the loss coefficients. Thus applying the correct loss coefficients is key to obtaining accurate flow distribution and pressure drops in the stator. The flow circuit can be broken down to a series of short pipes, Tjunctions and bends. The following sub-sections investigate the theory behind the loss coefficients for these components and give the contribution of each to flow mal-distribution. 


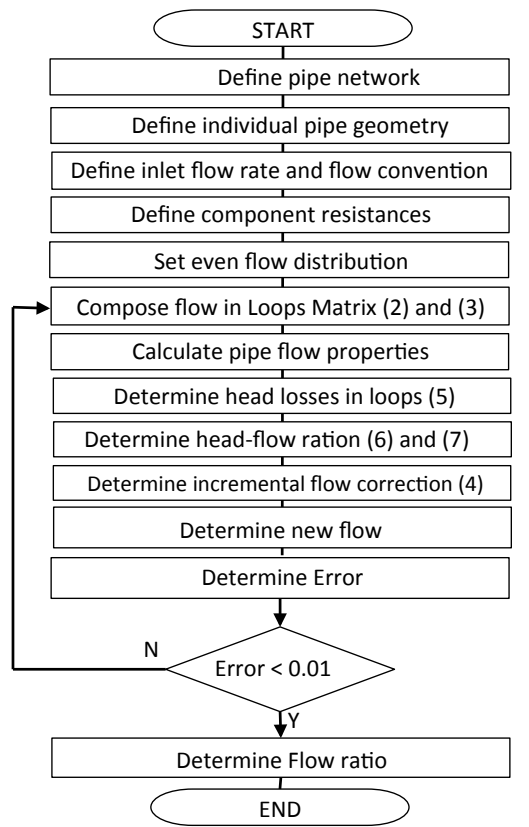

Fig. 4. Flow chart showing the process to solve the iterative 1D flow model for each sector

\section{1) The friction factor}

At the entry of a fluid into a pipe, the no slip condition at the wall dictates that the fluid velocity at the wall is zero. Thus the fluid at the center of the flow accelerates to preserve the continuity of mass. This is referred to as the developing flow and occurs along an entry length $L_{\mathrm{e}}$ until the velocity profile becomes parabolic. In laminar flow, the entry length is approximately 20 diameters long and is defined in [35] by:

$$
L_{\mathrm{e}}=0.05 \operatorname{Re} . D_{\mathrm{h}}
$$

Re is the Reynolds number defined as:

$$
\operatorname{Re}=\frac{v_{f} D_{\mathrm{h}}}{v}
$$

$D_{\mathrm{h}}$ is the hydraulic diameter defined as:

$$
D_{\mathrm{h}}=\frac{4 A}{p}
$$

Kays [28] shows that the head loss in the entry region of a laminar flow can be evaluated using:

$$
h_{\mathrm{f}, \mathrm{i}}=\frac{\left(4 f_{\mathrm{app}}\right) L_{\mathrm{e}} \cdot v_{f}^{2}}{2 g D_{\mathrm{h}}}
$$

$f_{\text {app }}$ incorporates the combined effects of shear stress at the wall surface and changes in momentum flux associated with changes in velocity profile. A correlation for $f_{a p p}$ has been developed in [36] such that:

$$
4 f_{\text {app }}\left(L_{\mathrm{e}} / D_{\mathrm{h}}\right)=29.979\left(\frac{L_{\mathrm{e}} / D_{\mathrm{h}}}{\mathrm{Re}}\right)^{0.6189}
$$

A comparison between the developed and developing friction factors shown in [36], [37] show that the pressure losses in developing flows can be up to 10 times larger than those in developed flows.

\section{2) Losses from T-junctions and bends}

Combining and dividing manifolds are typically considered as a minor source of head loss however in small systems their contribution may become significant. This phenomenon is governed by flow separation from the walls and becomes more pronounced with decreasing velocity. The variation of the loss coefficients with flow and area ratio for each of the branches in a T-junction has been investigated in [38]. A table 'look up and interpolate' function was developed for each of the dividing and combining branches respectively. This selects the correct loss coefficient at each iterative step. The head losses across each of the combining and dividing branches in Tjunctions was determined using:

$$
h_{\mathrm{f}, \mathrm{i}}=K \cdot \frac{v_{f_{\mathrm{i}}}{ }^{2}}{2 g}
$$

In which the loss coefficient $\mathrm{K}$ takes a different value depending on the direction of the flow [38].

\section{B. The lumped parameter thermal model}

Assuming that the pole pieces are made of a single homogenous material, the lumped parameter model was used to determine the average steady-state temperature for each pole piece, and thus the temperature distribution of the stator. The lumped parameter technique is based on the assumption of a spatially uniform temperature distribution and solves the heat equation:

$$
\frac{\mathrm{d} T_{\mathrm{p}}}{\mathrm{d} t}=\left(\frac{1}{\rho v c}\right) \cdot\left[\frac{\left(T-T_{\mathrm{f}}\right)}{R_{\mathrm{th}}}+\dot{E}_{\mathrm{g}}\right]
$$

where $\mathrm{d} T_{\mathrm{p}} / \mathrm{d} t$ is the rate of change of pole piece temperature, $\rho v c$ is the thermal capacitance of each pole piece while $R_{\mathrm{th}}$ is the convective thermal resistance. $\dot{E}_{\mathrm{g}}$ is the total heat losses generated in each of the segmented pole pieces. The fluid temperature $T_{\mathrm{f}}$ was taken as the temperature at the inlet of each quadrant where each pole piece was located. The fluid properties were also adjusted with quadrant inlet temperature. Table II shows the variation of the fluid properties with temperatures. The $4^{\text {th }}$ order Runge-Kutta method was used to solve the differential equation.

TABLE II

VARIATION OF COOLANT PROPERTIES WITH TEMPERATURE T $\left[{ }^{\circ} \mathrm{C}\right]$

\begin{tabular}{ll}
\hline \hline Density, $\rho\left[\mathrm{kg} / \mathrm{m}^{3}\right]$ & $\rho=-0.0052 T^{2}+0.2667 T+786.76$ \\
Dyn. visc. $\mu[\mathrm{Pa} . \mathrm{s}]$ & $\mu=0.0079 e^{-0.02 T}$ \\
Heat Capacity, $c$ & $c=-0.028 T^{2}+6.9105 T+2044.9$ \\
$\begin{array}{l}\mathrm{J} / \mathrm{kgK}] \\
\text { Thermal conductivity, } k\end{array}$ & $k=1 e^{-7} T^{2}-8 e^{-5} T+0.1376$ \\
{$[\mathrm{~W} / \mathrm{mK}]$} &
\end{tabular}

\section{Coupling the flow and thermal models}

The thermal resistance $R_{\text {th }}$ is heavily dependent on the flow properties and was used to couple the fluid model and thermal model. With the flow properties and flow distribution determined, the empirical equation for the Nusselt number $\mathrm{Nu}$ for a fluid with Prandtl number $>5$ and a developing thermal and fluid boundary layer was applied as suggested in [39]: 


$$
\mathrm{Nu}=\mathrm{K}_{\mu, \mathrm{i}}\left[3.66+\frac{0.0668 \cdot \operatorname{Pr} \cdot \operatorname{Re}_{\mathrm{i}} \cdot\left(\frac{D_{\mathrm{h}}}{L}\right)_{\mathrm{i}}}{1+0.04 \cdot\left(\operatorname{Pr} \cdot \operatorname{Re}_{\mathrm{i}} \cdot\left(\frac{D_{\mathrm{h}}}{L}\right)_{\mathrm{i}}\right)^{0.667}}\right]
$$

The factor $\mathrm{K}_{\mu, \mathrm{i}}$ is a corrective factor to take the variation of the coolant properties with temperature. Yang [40] defines the corrective factor as:

$$
\mathrm{K}_{\mu}=\left(\frac{\mu_{\mathrm{s}}}{\mu_{\mathrm{f}}}\right)^{-0.14}
$$

In which $\mu_{\mathrm{s}}$ is the viscosity at the surface temperature and $\mu_{\mathrm{f}}$ is the reference fluid viscosity at its local temperature. Due to the flow distribution problem, defining the local fluid temperature is difficult. Therefore in this work the temperature at each quadrant inlet is considered as a reference. This is easier to calculate as all the flow passes through this location. The corrective factor $\mathrm{K}_{\mu}$ was defined for each flow channel. As during the LP analysis, the solid temperature increases with time, a new $\mathrm{K}_{\mu}$ for each channel is calculated at each time step. The heat transfer coefficient for each side of the pole piece $\mathrm{HTC}_{\mathrm{i}}$ is determined from:

$$
\mathrm{HTC}_{\mathrm{i}}=\frac{\mathrm{Nu} \cdot k}{D_{\mathrm{h}}}
$$

The overall heat transfer coefficient $U$ for each pole piece was determined using:

$$
\mathrm{U}=\sum \mathrm{HTC}_{\mathrm{i}} \cdot A_{\mathrm{i}}
$$

$A_{\mathrm{i}}$ is the area for each side of the pole piece. The average thermal resistance for each pole piece is determined as:

$$
R_{\mathrm{th}}=\frac{1}{\mathrm{U}}
$$

Fig. 5 shows the process flow chart for the thermal model. It can be seen how the model considers each of the segmented pole pieces as a lump and is designed to provide an overall temperature distribution of the segmented stator. The thermal resistance is therefore independent of the thermal conductivity of the stator. Hence this has no effect on the simulated results.

\section{EXPERIMENTAL WORK}

\section{A. Experimental setup and temperature measurements}

A representative experiment of a quadrant of the stator highlighted in Fig. 2 was set up. The test rig is shown in Fig. 6. To eliminate potential errors related to temperature measurement and distribution within each pole piece, aluminum pieces were machined with the correct geometry to replace the segmented stator pole pieces. As the flow regime is very laminar at a Reynolds number of approx. 200, small differences in the surface finish between actual pole pieces with epoxy and the machined aluminum pieces do not produce significant differences to the HTC. Each aluminum piece was fitted with a $230 \mathrm{~V}, 150 \mathrm{~W}$ cartridge heater to simulate the total internal heat generation. This setup satisfies the scope of this work: to produce a means of validating a numerical model that produces a fast and accurate general temperature overview of the stator.

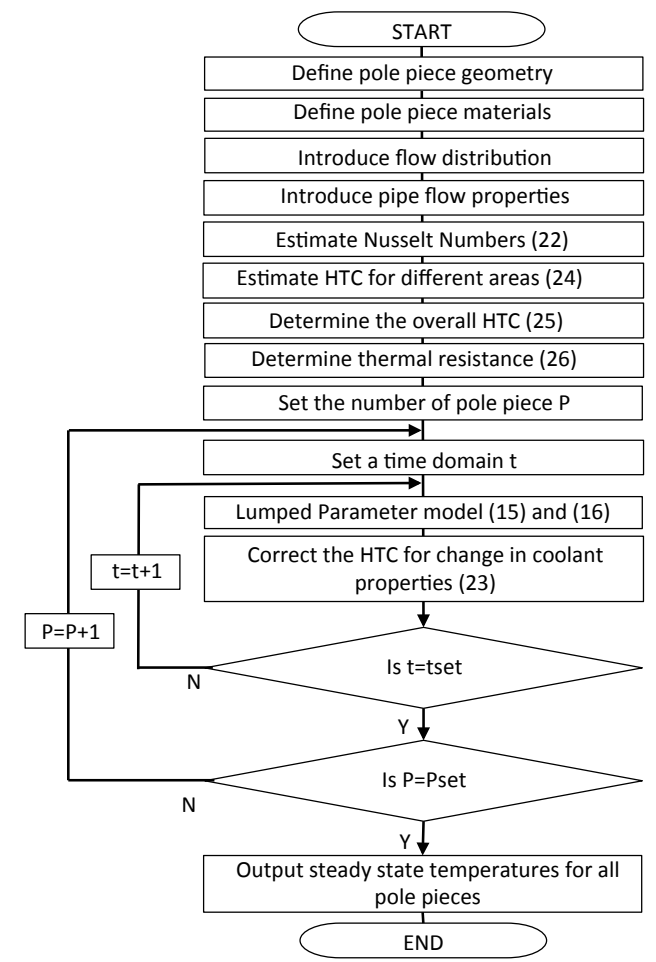

Fig. 5. Flow chart showing the process to solve the iterative LP thermal model

Silicone based thermal interface material was applied to improve the heat transfer between the heater and the pole pieces. Each pole piece was drilled with two $1 \mathrm{~mm}$ holes and fitted with two temperature sensors. The pole pieces were assembled on a plastic base in a test box, recreating the flow channels between them. The plastic base ensured that heat transfer to the test box was limited. The pole piece heaters were connected to a variable transformer, which was used to regulate the heat input. Current meters and a differential voltage probe were used to measure the current and voltage supplied to the heaters using a PicoScope 3000 series oscilloscope recording at $1 \mathrm{~Hz}$. The heat input $\mathrm{P}$ was calculated as:

$$
\mathrm{P}=\mathrm{I} . \mathrm{V}
$$

$\mathrm{I}$ and $\mathrm{V}$ are the d.c. measured current and voltage supplied to the heaters. Pico data loggers were used to record pole piece temperatures at $1 \mathrm{~Hz}$.

The coolant was re-circulated from a reservoir into the test rig and then pumped through a heat exchanger, expelling heat to ambient. The reservoir was also fitted with a heating element to control the inlet temperature of the fluid into the test section. The power input to the coolant heater was also regulated through a transformer. The flow rate was regulated using a globe valve and measured using a variable area flow meter, as shown in Fig. 7. Each experiment was run for approximately 3 hours to achieve steady state conditions. The steady state values across the final hour were then averaged to determine the temperature distribution of the pole pieces. The experiment was repeated for various coolant flow rates, inlet temperatures and pole piece heat losses, shown in Table III. 
TABLE III

EXPERIMENT DETAILS

\begin{tabular}{cccc}
\hline \hline Test No. & $\begin{array}{c}\text { Coolant inlet } \\
\text { temperature } \\
{\left[{ }^{\circ} \mathrm{C}\right]}\end{array}$ & $\begin{array}{c}\text { Flow rate } \\
{[\mathrm{lpm}]}\end{array}$ & $\begin{array}{c}\text { Pole piece heat } \\
\text { input }[\mathrm{W}]\end{array}$ \\
\hline 1 & 24.58 & 0.96 & 81.06 \\
2 & 22.96 & 0.96 & 148.14 \\
3 & 23.57 & 1.67 & 81.14 \\
4 & 24.85 & 1.77 & 152.27 \\
\hline 5 & 40.47 & 1.00 & 82.02 \\
6 & 40.83 & 1.16 & 148.36 \\
7 & 40.06 & 1.76 & 82.11 \\
8 & 41.52 & 1.99 & 148.89 \\
\hline
\end{tabular}

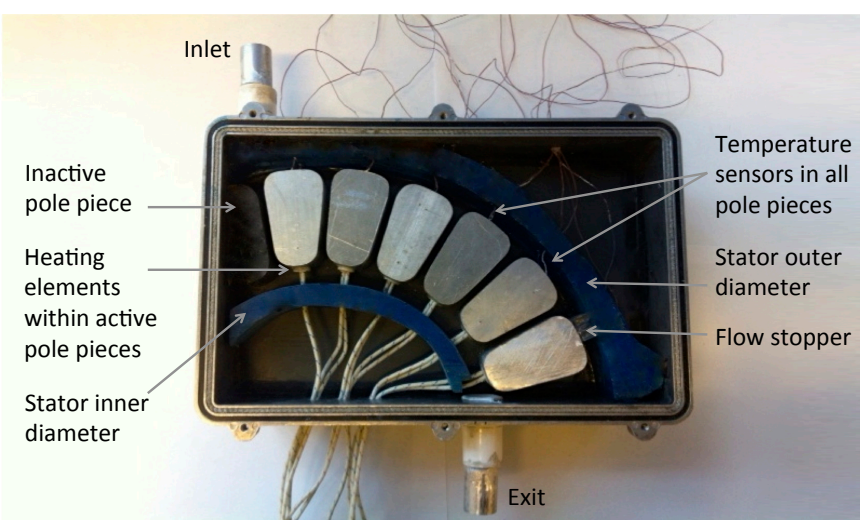

Fig. 6. Test piece representing the first quarter of the motor

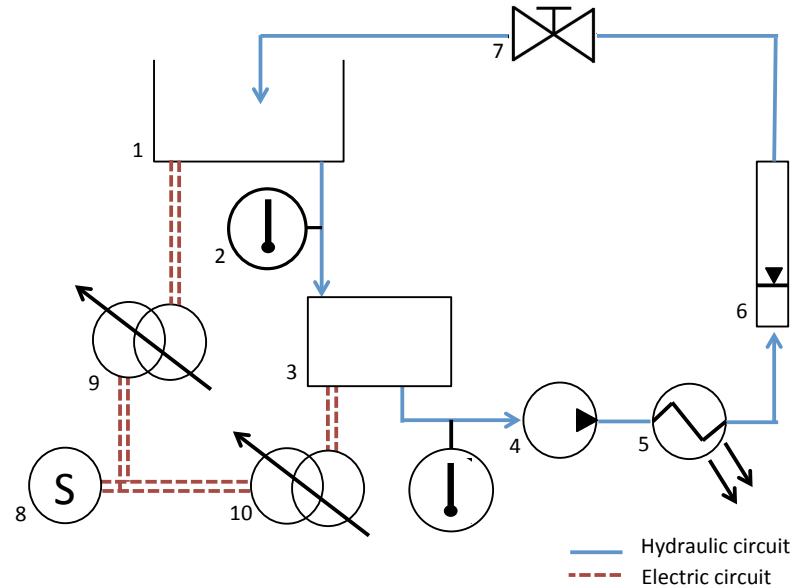

Fig. 7. Test setup with 1) oil reservoir, 2) temperature sensors, 3) test box, 4) pump, 5) heat exchanger, 6) variable area flow meter, 7) globe valve, 8) ac power supply, 9) variable transformer to power fluid heater, 10) variable transformer to power pole piece heaters.

To the authors' knowledge, no previous similar experimental work investigating direct oil cooled electrical machines has been presented.

\section{B. Calibration of the temperature sensors}

A calibration procedure for the T-type thermocouples was performed in which the test setup was mounted with thermocouples and inserted into a Carbolite oven. The thermocouples and data acquisition system were calibrated against a reference PT100 temperature sensor with an accuracy of $\pm 0.05 \mathrm{~K}$, for a range of temperatures from $20{ }^{\circ} \mathrm{C}$ to $180{ }^{\circ} \mathrm{C}$. The oven hysteresis was measured at $0.1 \mathrm{~K}$, while the thermocouple offset was measured at $0.33 \mathrm{~K}$.

\section{Calibration of the flow meter}

Variable area flow meters are calibrated for water. Therefore a recalibration process to account for the density and viscosity of the cooling oil was required. The calibration by weight method was used [41], [42] using the setup shown in Fig. 8. With the position of the flow meter noted, the mass of fluid collected was measured and timed. The calibration process was repeated for a number of inlet temperatures. A relationship for the flow rate with float position at different temperatures was derived.

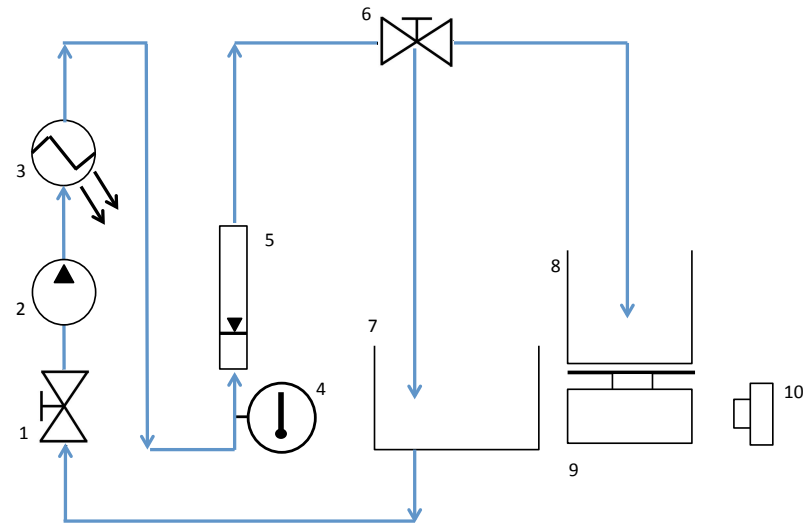

Fig. 8. Schematic showing flow meter calibration by mass using 1) gate valve, 2) pump, 3) heat exchanger, 4) thermometer, 5) flow meter, 6) 3-way valve, 7) reservoir, 8) collecting beaker, 9) scales, 10) video camera

\section{Uncertainty Analysis}

The temperature sensor uncertainty $\mathrm{u}(\mathrm{T})$ was calculated using:

$$
\mathrm{u}(\mathrm{T})=\sqrt{\left[u\left(T_{\mathrm{TC}}\right)\right]^{2}+\left[u\left(T_{\mathrm{RT}}\right)\right]^{2}+\left[u\left(T_{\mathrm{OH}}\right)\right]^{2}}
$$

In which the $u\left(T_{\mathrm{TC}}\right)$ is the thermocouple offset, $u\left(T_{\mathrm{RT}}\right)$ is the reference temperature accuracy and $u\left(T_{\mathrm{OH}}\right)$ is the oven hysteresis. The temperature uncertainty was calculated to be $0.35 \mathrm{~K}$. The uncertainty in the voltage meter $u(V)$ was $\pm 0.2 \mathrm{~V}$ while the uncertainty in the current meter $u(I)$ was $\pm 0.01 \mathrm{~mA}$. The uncertainty of the heat load $\mathrm{u}(\mathrm{P})$ was calculated as:

$$
\mathrm{u}(\mathrm{P})=\sqrt{[u(V) \cdot I]^{2}+[u(I) \cdot V]^{2}}
$$

The uncertainty of heat input was found to be $4 \mathrm{~mW}$ at low heat flux and $33 \mathrm{~mW}$ at the high heat flux. The uncertainty of the calibration scales was $1 \mathrm{mg}$ with a reading error of $0.01 \mathrm{~g}$. The stopwatch used in the flow calibration has an uncertainty $u(t)$ of $\pm 0.1 s$. The uncertainty in the flow meter $u\left(Q_{f m}\right)$ was $0.1 \mathrm{lpm}$. Hence the uncertainty in flow rate measurement $\mathrm{u}(\mathrm{Q})$ was calculated at:

$$
\mathrm{u}(\mathrm{Q})=\sqrt{[u(Q) \cdot t]^{2}+[u(t) \cdot Q]^{2}+\left[u\left(Q_{f m}\right)\right]^{2}}
$$

The uncertainty of the measured flow rate is $\pm 0.114 \mathrm{lpm}$.

\section{MOdel VALIDATION}

To validate the numerical model, the flow and temperature distribution within a quarter motor were simulated using the inlet conditions shown in Table III. The measured and predicted pole piece temperatures are compared in Table IV and Table V. The simulated pole piece temperatures are within $6 \%$ of the measured pole piece temperatures. 
TABLE IV

MeAsured and Predicted Pole Piece Temperatures for a CoOlant Inlet Temperature of $24^{\circ} \mathrm{C}$

\begin{tabular}{cccccccc}
\hline \hline Test No. & Pole piece No. & 1 & 2 & 3 & 4 & 5 & 6 \\
\hline \multirow{2}{*}{1} & Measured temp. $\left[{ }^{\circ} \mathrm{C}\right]$ & 90.37 & 94.51 & 97.34 & 96.96 & 99.91 & 105.92 \\
& Predicted temp. $\left[{ }^{\circ} \mathrm{C}\right]$ & 91.93 & 101.31 & 102.28 & 102.52 & 101.95 & 104.36 \\
\hline \multirow{2}{*}{2} & Measured temp. $\left[{ }^{\circ} \mathrm{C}\right]$ & 124.08 & 133.92 & 138.62 & 142.40 & 150.25 & 155.06 \\
& Predicted temp. $\left[{ }^{\circ} \mathrm{C}\right]$ & 124.18 & 138.68 & 141.22 & 142.22 & 143.59 & 147.06 \\
\hline \multirow{2}{*}{3} & Measured temp. $\left[{ }^{\circ} \mathrm{C}\right]$ & 80.28 & 87.21 & 90.04 & 87.37 & 86.37 & 90.10 \\
& Predicted temp. $\left[{ }^{\circ} \mathrm{C}\right]$ & 76.28 & 85.24 & 86.47 & 87.02 & 86.96 & 89.39 \\
\hline \multirow{2}{*}{4} & Measured temp. $\left[{ }^{\circ} \mathrm{C}\right]$ & 111.90 & 124.82 & 132.07 & 127.14 & 132.49 & 131.21 \\
& Predicted temp. $\left[{ }^{\circ} \mathrm{C}\right]$ & 112.24 & 125.90 & 127.68 & 128.39 & 128.11 & 131.77 \\
\hline
\end{tabular}

TABLE V

Measured and Predicted Pole Piece Temperatures for a CoOlant Inlet Temperature of $40{ }^{\circ} \mathrm{C}$

\begin{tabular}{|c|c|c|c|c|c|c|c|}
\hline Test No. & Pole piece No. & 1 & 2 & 3 & 4 & 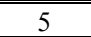 & 6 \\
\hline \multirow[t]{2}{*}{5} & Measured temp. $\left[{ }^{\circ} \mathrm{C}\right]$ & 103.52 & 113.71 & 112.50 & 112.03 & 114.40 & 116.77 \\
\hline & Predicted temp. $\left[{ }^{\circ} \mathrm{C}\right]$ & 101.85 & 112.17 & 113.77 & 114.68 & 113.98 & 116.07 \\
\hline \multirow[t]{2}{*}{6} & Measured temp. $\left[{ }^{\circ} \mathrm{C}\right]$ & 136.88 & 151.77 & 152.11 & 151.81 & 157.66 & 159.79 \\
\hline & Predicted temp. $\left[{ }^{\circ} \mathrm{C}\right]$ & 136.52 & 151.31 & 153.29 & 154.2 & 154.13 & 157.66 \\
\hline \multirow[t]{2}{*}{7} & Measured temp. $\left[{ }^{\circ} \mathrm{C}\right]$ & 93.42 & 107.25 & 104.77 & 101.43 & 101.85 & 99.57 \\
\hline & Predicted temp. $\left[{ }^{\circ} \mathrm{C}\right]$ & 91.93 & 101.31 & 102.28 & 102.52 & 101.95 & 104.36 \\
\hline \multirow[t]{2}{*}{8} & Measured temp. $\left[{ }^{\circ} \mathrm{C}\right]$ & 123.60 & 143.06 & 141.21 & 138.09 & 140.56 & 138.80 \\
\hline & Predicted temp. $\left[{ }^{\circ} \mathrm{C}\right]$ & 124.30 & 138.49 & 139.87 & 140.23 & 138.00 & 141.08 \\
\hline
\end{tabular}

\section{Simulation Of The Motor And IMPROVEMENTS}

\section{A. Simulation of the motor}

Following the validation of the model, this was adapted to reflect the geometry of a full machine stator as shown in Figs. 2 and 3 . The motor was simulated with an inlet coolant flow rate of $6 \mathrm{lpm}$ and a coolant inlet temperature of $80{ }^{\circ} \mathrm{C}$. The manufacturer's efficiency chart [31] was used to derive the stator heat losses associated with a nominal operating point of $1500 \mathrm{rpm}$ and $400 \mathrm{~N} \cdot \mathrm{m}$. The stator temperature for the original motor design is shown in Fig. 9.

\section{B. Improvements to the temperature distribution}

The changes in flow geometry are found to affect the temperature distribution as follows:

- Decreasing the width of the outer and inner fluid paths increases the head loss from the paths, forcing a larger portion of the flow through the pole piece channels. This increasing the flow velocity and the HTC, reducing the pole piece temperatures.

- The flow distribution is determined by the relative head losses of the pipes. By increasing the head losses in the rings, an uneven flow distribution (and temperature distribution) occurs, creating hot spots in the segmented stator pole pieces.

- The flow distribution in the stator can be altered by introducing flow-restricting components at specific locations within the inner and outer rings.

The inner and outer rings of the original YASA flow geometry shown in Fig. 2 was reduced to $8 \mathrm{~mm}$. Flowrestricting components were introduced along these rings. As a result of these changes, the temperatures of the segmented stator were reduced as shown in Fig 9. The maximum hotspot temperature was reduced by approximately $13 \mathrm{~K}$. The improved stator flow geometry is shown in Fig. 10.

\section{DISCUSSION AND CONCLUSION}

This paper develops a fast and accurate numerical simulation tool to predict the overall temperature distribution of a

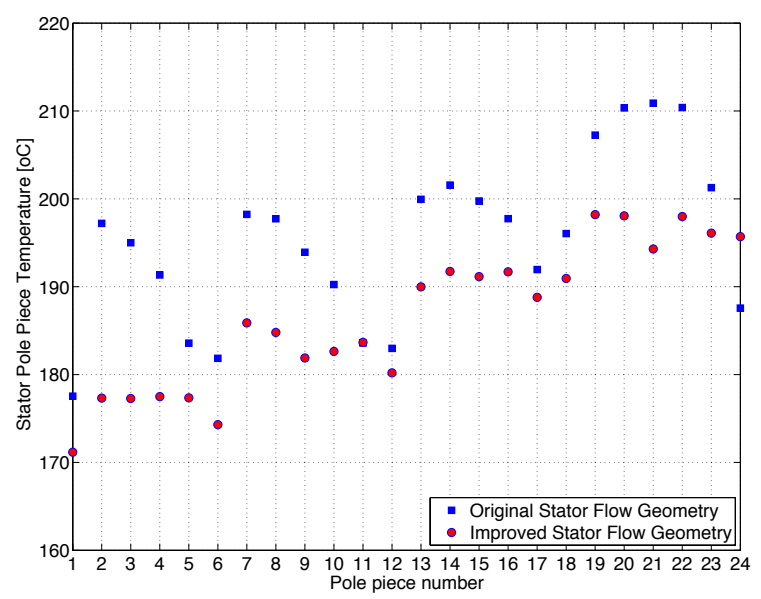

Fig. 9. Predicted stator pole piece temperatures for a coolant flow rate of 6 lpm, coolant inlet temperature of $80^{\circ} \mathrm{C}$, motor operating conditions at constant $1500 \mathrm{rpm}$ and $400 \mathrm{~N} \cdot \mathrm{m}$

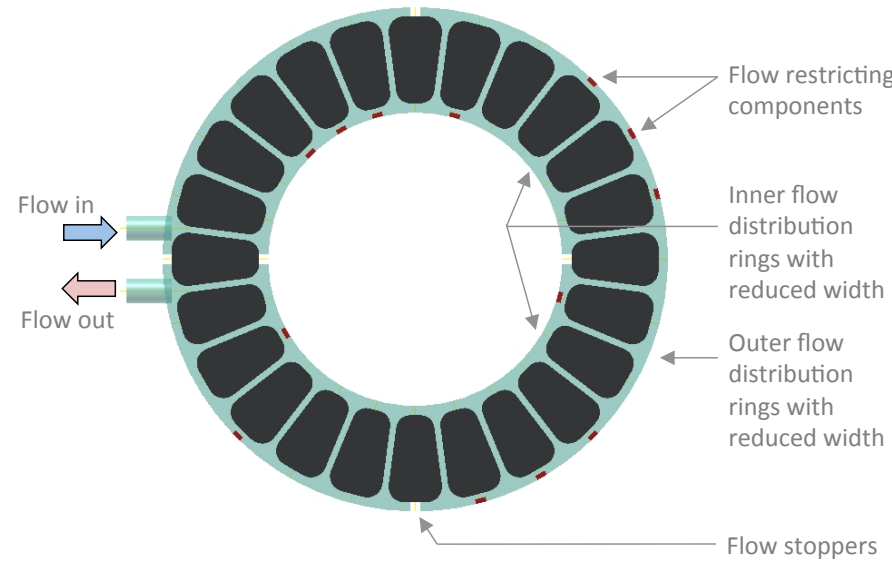

Fig. 10. The resulting stator flow geometry achieving an improved temperature distribution.

segmented stator. The model was validated with experimental measurements on a quarter-model of the stator. The developed model provides the thermal designer with an overview of the thermal distribution of the segmented stator at a very early 
design stage of the machine. The model allows the thermal designer to investigate the effects that different geometrical, boundary and operational conditions have on the temperature distribution of the stator. It is shown how by controlling the flow distribution in the stator, the temperature distribution is improved and the hotspot temperature reduced. This can be used to benefit the motor in one of two ways:

1. Increase the lifetime of winding insulation.

The insulation varnish on the copper windings is located directly at the hotspots of the segmented pole pieces and is therefore situated at the most demanding location [43]. Thermal ageing of insulation is commonly estimated by the Arrhenius reaction rate equation [5] with practical insulator experiments showing that a temperature rise of approximately $10 \mathrm{~K}$ reduces the life expectancy by half [43]. The model was used to improve the stator flow geometry and reduce the hot spot temperature by $13 \mathrm{~K}$, roughly doubling the lifetime of the stator insulation.

2. Increase the current density of the machine

Conversely, the new stator geometry could be used at a higher current density. By improving the stator flow geometry, it was found that the pole piece heat losses in the new stator design could be increased by $13 \%$ before the same hotspot temperature as the old geometry is reached. Assuming that in a low speed machine the ratio of rotor and iron losses remains constant with a small increase in current, a simultaneous equation in terms of the $I^{2} R$ losses is formed.

Since the resistance will be at the same hotspot temperature, the current in the new stator geometry can be described as a factor of the current in the old stator geometry:

$$
I_{\text {new }}=1.066 I_{\text {old }}
$$

Therefore with the new stator design the current density is increased by about $7 \%$.

\section{ACKNOWLEDGEMENTS}

The authors would like to thank Mr. Robin Vincent, Mr. Cleveland Williams and Mr. Maurice Keble Smith for their input during the design and manufacturing of the experiment. Funding and support from Seifert Systems Malta Ltd is acknowledged and appreciated.

\section{REFERENCES}

[1] T.J. Woolmer and M.D. McCulloch, "Analysis of the yokeless and segmented armature machine" in IEMDC'07, Antalya, Turkey, 2007, pp. 704708.

[2] S.T. Vun, M.D. McCulloch and C.Y. Leong, "The development of an electromagnetic analytical design tool for megawatt-scale YASA generators" in RPG2011, Edinburgh, UK, 2011, pp. 1-6.

[3] M. Lamperth, A. Beaudet and M. Jaensch, "Disc motors for automotive applications", in HEVC2008, Coventry, UK, 2008, pp. 1-5.

[4] A. Boglietti, "Guest Editorial", IEEE Trans. Ind. Electron., Vol. 55, pp. 3498-3499, 2008.

[5] T.W. Dakin, "Electrical Insulation Deterioration treated as a Chemical Rate Phenomena", AIEE Trans. Part 1 (Communications and Electronics) Vol. 67, pp. 113-122, 1948.

[6] T.A. Jankowski, F.C. Prenger, D.D. Hill, S.R. O’Bryan, K.K. Sheth, E.B. Brookband, D.F.A. Hunt, Y.A. Orrego, "Development and Validation of a Thermal Model for Electric Induction Motors", IEEE Trans. Ind. Electron. Vol. 57, No. 12, pp. 4043 - 4054, Dec. 2010.

[7] J. Nerg, M. Rilla, J. Pyrhonen, "Thermal Analysis of Radial Flux Electrical Machines with a High Power Density", IEEE Trans. Ind. Electron.
Vol. 55, No. 10, pp. 3543 - 3554, Oct. 2008

[8] A. Tessarolo, C. Bruzzese, "Computationally Efficient Thermal Analysis of a Low-Speed High-Trust Linear Electric Actuator with a ThreeDimensional Thermal Network Approach", IEEE Trans. Ind. Electron., Vol. 62, No. 3, pp. 1410-1420, Mar. 2015.

[9] F. Marignetti, V.D. Colli, and Y. Coia, "Design of axial flux PM synchronous machines through 3-D coupled electromagnetic thermal and fluiddynamical finite-element analysis", IEEE Trans. Ind. Electron., Vol. 55, no. 10, pp. 3591-3601, Oct. 2008

[10] T.D. Kefalas, A.G. Kladas, "Thermal Investigation of Permanent-Magnet Synchronous Motor for Aerospace Applications", IEEE Trans. Ind. Electron., Vol. 61, No. 8, pp. 4404 - 4411, Aug. 2014.

[11] X. Sun, M, Cheng, "Thermal Analysis and Cooling System Design of Dual Mechanical Port Machine for Wind Power Application”, IEEE Trans. Ind. Electron. Vol. 60, No. 5, pp. 1724-1733, May 2013

[12] R. Wrobel and P.H. Mellor, "Thermal design of high energy density wound components", IEEE Trans. Ind. Electron. Vol. 58, No. 9, pp. 40964104, Sept. 2011

[13] U. SanAndres, G. Almandoz, J. Poza, G. Ugalde, "Design of Cooling Systems Using Computational Fluid Dynamics and Analytical Thermal Models", IEEE Trans. Ind. Electron., Vol. 61, No. 8, pp. 4383-4391, Aug. 2014

[14] C. Jungreuthmayer, T. Bauml, O. Winter, M. Ganchev, H. Kapeller, A. Haumer, C. Kral, "A Detailed Heat and Fluid Flow Analysis of an Internal Permanent Magnet Synchronous Machine by Means of Computational Fluid Dynamics", IEEE Trans. Ind. Appl., Vol. 59, No. 12, pp. 4568-4578. Dec. 2012.

[15] C. Micallef, S. J. Pickering, K. A. Simmons and K. J. Bradley, "Improved cooling in the end region of a strip-wound totally enclosed fancooled induction electric machine", IEEE Trans. Ind. Electron., Vol. 55, No. 10, pp. 3517-3524, Oct. 2008.

[16] Y.C. Chong, E.J. Echenique Subiabre, M.A. Mueller, J. Chick, D.A. Staton, A.S. McDonald, "The Ventialtion Effect on Stator Convective Heat Transfer of an Axial-Flux Permanent Magnet Machine", IEEE Trans. Ind. Appl., Vol. 61, No. 8, pp. 4392-4403, Aug 2014.

[17] D.A. Howey, A.S. Holmes, K.R. Pullen, "Measurement and CFD Prediction of Heat Transfer in Air-Cooled Disc-Type Electrical Machines", IEEE Trans. Ind. Appl., Vol. 47, No. 4, pp. 1716-1723, Jul/Aug. 2011.

[18] J.G. Amoros, P. Andrada, B. Blanque, "An analytical approach to the thermal design of a double sided linear switched reluctance motor", in ICEM2010, Rome, Italy, 2010, pp. 1-4.

[19] C. Mejuto, M. Mueller, M. Shanel, A. Mebarki, M. Reekie, D. Staton, "Improved synchronous machine thermal modeling", in ICEM2008, Vilamoura, Portugal, 2008 pp. 1-6.

[20] M. Hettegger, B. Streibl, O. Biro, H. Neudorfer, "Measurements and Simulations of the Convective Heat Transfer Coefficients on the End Windings of an Electrical Machine", IEEE Trans. Ind. Electron., Vol. 59, No. 5, pp. $2299-2308$, May 2012

[21] D.A. Howey, A.S. Holmes, K.R. Pullen, "Measurement of stator heat transfer in air-cooled axial flux permanent magnet machines", in IECON'09, Porto, Portugal, 2009, pp. 1197-1202.

[22] D.A. Howey, P. R. N. Childs, A.S. Holmes, "Air-gap convection in rotating electrical machines", IEEE Trans. Ind. Electron., Vol. 59, No. 3, pp. 1367-1375, Mar. 2012.

[23] D.A. Staton, A. Cavagnino, Convection "Heat Transfer and Flow Calculations Suitable for Electric Machine Thermal Models", IEEE Trans. Ind. Electron., Vol. 55, No. 10, pp. 3509-3516, Oct, 2008.

[24] A. Boglietti, A. Cavagnino, D. Staton, M. Shanel, M. Mueller, C. Mejuto, "Evolution and Modern Approaches of Thermal Analysis of Electrical Machines", IEEE Trans. Ind. Electron., Vol. 56, No. 3, pp. 871-882, Mar. 2009.

[25] L. Szabo, M. Ruba, "Segmental Stator Switched Reluctance Machine for Safety-Critical Applications", IEEE Trans. Ind. Appl., Vol. 48, No. 6, pp. 2223-2229, Nov/Dec 2012

[26] Z.Q. Zhu, Z. Azar, G. Ombach, "Influence of Additional Air Gaps Between Stator Segments on Cogging Torque of Permanent-Magnet Machines Having Modular Stators", IEEE Trans. on Mag., Vol. 48, No. 6, pp. 20492055, June 2012

[27] R. Wrobel, P. Mellor, D. Holliday, "Thermal modelling of a segmented stator winding design", IEEE Trans. Ind. Appl., Vol 47, No. 5, pp. 2023-2030, Sept./Oct. 2011.

[28] H. Vansompel, P. Sergeant, L. Dupre, A. Van den Bossche, "A Combined Wye-Delta Connection to Increase the Performance of Axial-Flux PM Machines With Concentrated Windings", IEEE Trans. Energy Conv., Vol. 27, No. 2, pp. 403-410, Jun. 2012. 
[29] B. Zhang, M. Doppelbauer, "Numerical iron loss calculation of a new axial flux machine with segmented armature torus topology", in PEMD 2014, Manchester, UK, 2014, pp. 1-6.

[30] W. Fei, P. Luk, K. Jinupun, "A new axial flux permanent magnet segmented armature torus machine for in-wheel direct drive applications", in PESC2008, Rhodes, 2008, pp. 2197-2202.

[31] YASA Motors. Yasa Motors Products,

http://www.yasamotors.com/technology/products/, accessed on: 9/20, 2010.

[32] J.C.H. Bone, "Cooling and cooling circuits for electric motors", IEE J. on Elec. Power Appl., Vol 1, No. 2, 1978, pp. 37-44.

[33] J. L. Taylor, "Calculating Air Flow Through Electrical Machines", UK Electrical Times, 1960.

[34] H. Cross, "Analysis of Flow in Networks of Conduits or Conductors", University of Illinois Eng., Experiment Station, Vol. 286, 1936. [35] W. Kays, M. Crawford and B. Weigand, "Chapter 7: Laminar internal flows: Momentum transfer", in Convective Heat and Mass Transfer, 4th ed. New York: McGraw Hill Education, 2004, pp. 74-76.

[36] H. L. Langhaar, Steady Flow in the Transition of a Straight Tube, Journal of App. Mech., Vol. 64, 1942, pp. A55-A58.

[37] A. H. Shapiro, R. D. Smith and NACA, "Friction Coefficients in the Inlet Length of Smooth Round Tubes", 1948.

[38] D. S. Miller, "Dividing and combining flow", in Internal Flow Systems, 2nd ed. Cranfield, Bedford, UK: BHRA, 1990, pp. 303-319.

[39] F. Incropera, D. P. Dewitt, T. L. Bergman and A. S. Lavine, "Internal flow: Laminar flow in circular tubes; the entry region", in Introduction to Heat Transfer, 5th ed. New York: Wiley \& Sons Inc., 2007, pp. 482-483.

[40] K. T. Yang, "Laminar Forced Convection of Liquids in Tubes with Variable Viscosity", in Heat Transfer, Vol. 84, pp. 353-362, Nov. 1962. [41] APTI435. "Atmospheric Sampling Course; Theory and Calibration Procedures for the Use of a Rotameter",

http://www.epa.gov/eogapti1/Materials/APTI\%20435\%20student/Student $\% 20$ Manual/Appendix_F_no\%20TOC-cover_MRpf.pdf, accessed on: 6/13, 2012. [42] ISA-RP16.6-1961. "Methods and Equipment for Calibration of Variable Area Meters; Recommended Practice",

http://www.isa.org/Content/Microsites121/Standards_and_Practices_Departm ent_Board/Home119/Ballots/RP_166.pdf, accessed on: 13/6, 2012.

[43] J. Pyrhoenen, T. Jokinen, V. Hrabovcova, "Chapter 8, insulation of Electrical Machines", in Design of Rotating Electrical Machines, New York: Wiley \& Sons Inc., 2008.

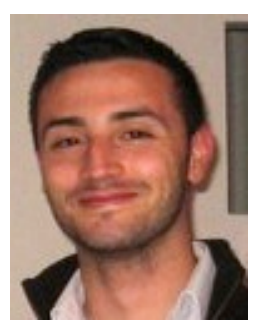

Robert Camilleri graduated in Mechanical Engineering from the University of Malta in 2005, and holds an MSc. in Gas Turbine Technology from Cranfield University. He has subsequently worked as a research engineer at Seifert Systems Malta Ltd, specializing in electronics cooling and heat exchangers. Robert joined the Energy and Power Group in 2010 as a Research Assistant. He is now completing his DPhil. in Engineering Science at the University of Oxford with his thesis focusing on Heat transfer in high current density electrical machines.

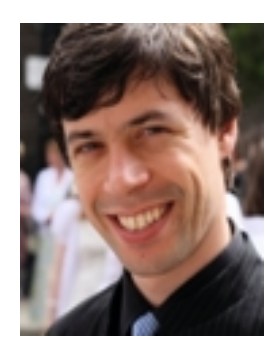

David A. Howey (M'10) received the B.A. and M.Eng. degrees from Cambridge University, Cambridge, U.K., in 2002 and the Ph.D. degree from Imperial College London, London, U.K., in 2010. $\mathrm{He}$ is currently an Associate Professor with the Energy and Power Group, Department of Engineering Science, University of Oxford, Oxford, U.K. His research is focused primarily on energy storage systems, including projects on model-based battery management, degradation, thermal management, and energy management for grid storage. He also undertakes research on thermal management and degradation of electrical machines.

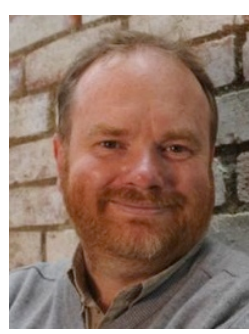

Malcolm D. McCulloch (M'89) was born in South Africa. He received the B.Sc. (Eng.) and Ph.D. degrees in electrical engineering from the University of Witwatersrand, Johannesburg, South Africa, in 1986 and 1990, respectively. In 1994, he headed up the Energy and Power

Group, University of Oxford, Oxford, U.K., where he has been active in the areas of electrical machines, transport, and smart grids. He is the Founder of three spinout companies arising out of his research activity. $\mathrm{He}$ has more than 100 journal and refereed conference papers, and has been an Invited Speaker at the world forum in Tianjin, 2010, and the Hindustan Leadership Conference, Delhi, in 2013. 